\title{
QUANDO OS ESTUDOS DO DISCURSO ENCONTRAM OS ESTUDOS LGBT
}

Iran Ferreira de Melo

(UFRPE)

\section{RESUMO}

Este trabalho tem caráter teórico-analítico e visa à identificação panorâmica dos estudos dos linguistas Michael Halliday \& Christian Matthiessen (2004) e Norman Fairclough (2001, 2003), observando os pontos de encontro e diferença entre as suas duas abordagens. Nós apresentaremos uma exposição comparativa por meio de quadros que demonstram os conceitos e as categorias linguísticas mais rentáveis sobre representação para esses cientistas. Aplicaremos ainda a proposta teórica desenvolvida por eles na análise de uma notícia sobre a representação da militância LGBT (lésbicas, gays, bissexuais, travestis e transexuais), com o intuito de verificar a relevância social e crítica da teoria preconizada pelos autores citados.

PALAVRAS-CHAVE: Linguagem. Multifuncionalidade. LGBT.

\section{Introdução}

Os estudos acerca da relação entre a língua e os contextos sociais mais amplos constituem, há algum tempo, investigações caras à Linguística e fazem dessa ciência uma arena produtiva de pesquisas que, por meio de vários paradigmas, ajudaram a repensar as teorias sobre o lugar da linguagem no estabelecimento das representações e identidades sociais. A relação entre discurso e sociedade, portanto, tem suscitado diversas abordagens no campo da Linguística contemporânea, sendo muitas delas destaques, por apresentarem interfaces complexas entre as Ciências Sociais e os estudos da linguagem e identificarem entre a prática discursiva e a prática social uma relação dialética e biunívoca.

Inserido nessa seara, este artigo objetiva apresentar a teoria sobre a multifuncionalidade da linguagem preconizada por Michael Halliday 
\& Christian Matthiessen (2004) e Norman Fairclough (2001, 2003), uma vez que, em seus estudos, esses pesquisadores tentam entender em que medida o discurso é parte integrante e, ao mesmo tempo, construtor, mantedor e transformador de várias práticas sociais. Seus trabalhos expõem que todo texto agrupa um compósito de três macrofunções responsáveis pela ordenação das informações, pela representação da realidade social, bem como pela construção de identidades e relações sociais. A seguir, discutiremos as similitudes e dessemelhanças entre os quadros teóricos desses dois linguistas na tentativa de compreender suas contribuições para 0 trabalho de análise crítica dos discursos contemporâneos sobre minorias sociais, notadamente aqueles empreendidos pelo domínio jornalístico acerca do ativismo LGBT.

\section{Por uma teoria multifuncional e crítica do discurso}

A concepção teórica que avaliza este estudo está vinculada aos postulados do que denominamos Análise Crítica do Discurso. Trata-se de uma abordagem teórico-metodológica da ivestigação linguística na sociedade contemporânea, cuja emergência se deu na segunda metade da década de 1980 a partir de estudos do linguista britânico Norman Fairclough (1985), mas firmando-se como perspectiva científica apenas no início dos anos 1990, com o advento de várias pesquisas que partilhavam o objetivo de entender a linguagem como uma prática social interconectada a outras da vida cotidiana, bem como de desvelar as relações de dominação e hegemonia produzidas discursivamente, descrevendo, interpretando e explicando os mecanismos de transformação dessas relações.

A Análise Crítica do Discurso (doravante ACD) é compreendida como uma abordagem funcionalista da Linguística, isto é, um paradigma de estudo que assegura o postulado de não-autonomia da linguagem, analisando o sistema interno da língua como parte irredutível de outros sistemas, a saber: a cognição, a conjuntura sócio-histórica e a cultura. Sendo assim, a ACD parte do pressuposto de que a estrutura da linguagem exerce funções extrínsecas ao seu sistema, ou seja, desenvolve relações de sentido com elementos que a amparam, mas que não são unicamente linguísticos.

Constitui-se funcionalista qualquer teoria linguística que descreve um texto associando as categorias que o compõem internamente - elementos referenciais, lexicais, icônicos, entre outros - a elementos do entorno de sua produção e consumo - como à cognição social e cultura dos 
interlocutores -, isso quer dizer que é funcionalista aquela corrente da Linguística que "não separa o sistema linguístico e suas peças das funções que têm de preencher [...] e reconhece, na instabilidade da relação entre estrutura e função, a força dinâmica que está por trás do constante desenvolvimento da linguagem" (NEVES, 1997, p. 03).

Desse modo, a ACD pode se utilizar da rubrica de funcionalista para entender como a linguagem exerce funções que ajudam a estabelecer o poder, a reprodução, a manutenção e a transformação da sociedade (FAIRCLOUGH, 1989, 2001, 2003). Para assegurar esse papel, ela se manifesta, por princípio, como uma abordagem transdisciplinar; "isso significa que não somente aplica outras teorias, como também, por meio do rompimento de fronteiras epistemológicas, operacionaliza e transforma tais teorias em favor da abordagem sociodiscursiva" (RESENDE \& RAMALHO, 2006, p.14). Dentre os postulados teóricos que a ACD usa, alguns são oriundos de outros paradigmas internos à própria Linguística e outros correspondem a disciplinas das Ciências Humanas que buscam entender o funcionamento da sociedade contemporânea. Destacaremos, aqui, a importância de um dos campos que influenciaram a ACD: a Linguística Sistêmico-funcional - vertente teórica desenvolvida pelo linguista Michael Halliday -, além de sua leitura feita pela Teoria Social do Discurso de Norman Fairclough (2001, 2003).

\section{A Teoria Social do Discurso de Fairclough}

Norman Fairclough, um dos mais ativos analistas críticos do discurso e fundador da $\mathrm{ACD}$, produziu um vasto material bibliográfico, que se tornou indispensável para a compreensão do que vêm a ser os estudos críticos da linguagem. Para o autor, fazer análise de discurso é descrever, interpretar e explicar como a vida social se realiza por meio da manifestação linguística, uma vez que o discurso consiste numa prática social interconectada a outras igualmente importantes que funcionam como partes constituintes da sociedade (FAIRCLOUGH, 2003). Desse modo, cabe a um/a analista crítico/a do discurso identificar os mecanismos que constituem as formações ideológicas imbricadas na formação de determinados modos de organização da linguagem. Em face disso, Fairclough (2001, 2003) reconhece que é de responsabilidade do/a analista crítico/a do discurso investigar as relações assimétricas de poder investidas na linguagem, fornecendo ferramentas de compreensão sobre os mecanismos que podemos usar para reverter tais desigualdades. 
Portanto, esse teórico, numa primeira fase de sua teoria, propôs um método que compreende a composição do discurso como simultaneamente três dimensões de análise: o texto, a prática discursiva e a prática social. Tal tríade deve ser entendida como uma realização única no funcionamento do discurso, porém analisada separadamente e sob perspectivas sistematicamente definidas, para tanto, Norman Fairclough (2001) aponta os seguintes elementos de compreensão das três dimensões:

\begin{tabular}{|l|l|l|}
\hline Texto & $\begin{array}{l}\text { Prática discursiva } \\
\text { Produção } \\
\text { (pressupostos, } \\
\text { atos de fala, } \\
\text { implicaturas) }\end{array}$ & Hegemonia \\
\hline $\begin{array}{l}\text { Operadores de } \\
\text { coesão }\end{array}$ & $\begin{array}{l}\text { Consumo } \\
\text { (ativação de conhecimentos) }\end{array}$ & Ideologia \\
\hline $\begin{array}{l}\text { Operadores } \\
\text { argumentativos }\end{array}$ & $\begin{array}{l}\text { Intertextualidade } \\
\text { e interdiscursividade }\end{array}$ & Aspectos \\
\cline { 1 - 2 } culturais
\end{tabular}

Quadro 1 - Perspectiva tridimensional do discurso de Norman Fairclough (ACD)

Com esse postulado, tal linguista apresenta o limiar daquilo que denomina Teoria Social do Discurso, uma abordagem de análise dos discursos que compreende a formação das três dimensões acima citadas, com o objetivo de estabelecer uma teoria linguística que forneça dados relevantes para as Ciências Sociais, haja vista se preocupar com o texto não apenas em sua versão estrutural, mas também na sua face organizacional, ou seja, de produção e consumo - discursiva - e em sua função 
eminentemente social, isto é, como uma prática comum e concreta à nossa vida cotidiana.

Nesse sentido, Fairclough reconheceu, em sua teoria, o valor fundamental da dialética que o discurso estabelece com a sociedade em geral, ou seja, sendo constituído e, ao mesmo tempo, construtor das representações sociais, das identidades e dos sistemas de crença e conhecimento. A partir disso, o cientista britânico, distingue o lugar da Linguística em sua teoria, identificando sua perspectiva de estudo como, acima de tudo, textual. Isso quer dizer que, embora Fairclough visualize a relação biunívoca que o discurso mantém com a sociedade, ele firma sua teoria sem perder de vista que se trata de um estudo do texto.

Em virtude disso, designou o seu modo de investigar a linguagem de Análise do Discurso Textualmente Orientada (ADTO), a qual, distinguindo-se de outras abordagens críticas do discurso que focalizam a cognição em suas análises, é tributária tanto de teorias das Ciências Sociais quanto de postulados da Linguística, em especial a Linguística Sistêmico-Funcional (doravante LSF), da qual trataremos a seguir.

\section{0 legado da LSF para a ACD}

Michael Halliday é autor da teoria sistêmico-funcional da linguagem, com a qual declarou que o significado das estruturas linguísticas não pode ser dissociado do valor social que possui e que as realizações textuais desses significados devem ser incluídas no escopo da descrição gramatical. Além disso, registrou que o funcionamento dos textos tem uma organização triádica e simultânea, isto é, possui três macrofunções responsáveis pelo valor social da linguagem, são elas: textual, ideacional e interpessoal.

A função textual refere-se ao fluxo informacional do texto por meio da ordem de elementos no enunciado, que indicam o propósito comunicativo e o destaque que o falante quer oferecer em seu texto, sendo estudada a partir da análise do processo de tema/rema. A função ideacional da linguagem corresponde ao papel de representar a realidade que a língua possui, pois, segundo Halliday \& Matthiessen (2004), os enunciados refletem eventos, ações, estados, indivíduos e diversos processos da atividade humana através de alguns recursos linguísticos, como o léxico e, principalmente, a transitividade. Já a função interpessoal é responsável por estabelecer a interação social, auxiliando na construção das relações sociais e das identidades dos interlocutores por meio de categorias lin- 
guísticas que apontam o grau de envolvimento dos falantes com o que dizem, por exemplo, os modalizadores. O quadro a seguir resume essa exposição.

\begin{tabular}{|l|l|}
\hline \multicolumn{2}{|l|}{ Halliday \& Matthiessen (2004) } \\
\hline $\begin{array}{l}\text { Função } \\
\text { ideacional }\end{array}$ & Léxico \\
\hline $\begin{array}{l}\text { Função } \\
\text { interpessoal }\end{array}$ & Modalizador \\
\hline Função textual & Tema/rema \\
\hline
\end{tabular}

Quadro 2 - Perspectiva multifuncional da linguagem na LSF

As três macrofunções, conforme esses autores, se realizam simultaneamente nos enunciados e são inter-relacionadas. Portanto, essa teoria parte do princípio de que todo enunciado é multifuncional e integrado.

Fairclough $(2001,2003)$ reconfigurou esse postulado a partir dos interesses da ACD. Inicialmente, reconheceu que a função interpessoal pode se desmembrar em duas outras: relacional - estabelece relações entre os interlocutores e entre estes e o objeto do discurso - e identitária - refere-se ao modo como os indivíduos são identificados no discurso. Segundo Fairclough (2001), o motivo dessa reelaboração está relacionado à importância do discurso na constituição, reprodução, contestação e reestruturação de identidades, o que, para ele, foi desconsiderado pala LSF. O quadro abaixo explana melhor essa mudança. 


\begin{tabular}{|l|l|l|}
\hline \multirow{2}{*}{ Fulliday \& Matthiessen } & (2004) & Fairclough (2001) \\
\hline \multirow{2}{*}{ Função ideacional } & Léxico & \multirow{2}{*}{ Função ideacional } \\
\cline { 2 - 3 } & Transitividade & \\
\hline Função textual & Modalizador & Função relacional \\
\cline { 2 - 3 } & & Função identitária \\
\hline
\end{tabular}

Quadro 3 - Multifuncionalidade da linguagem na LSF e na ACD

Em 2003, Fairclough amplia o diálogo teórico que fez com a teoria multifuncional do Halliday e propõe uma relação entre as macrofunções e os conceitos de discurso, gênero e estilo, sugerindo, em lugar das funções apresentadas por Halliday, três tipos de significados: representacional, identificacional e acional. Estes correspondem, respectivamente, às funções ideacional, identitária e relacional/textual. Fairclough justifica a união da relacional à textual por entender que esta última, mais do que apontar informações e propósitos constitui uma ação, tal qual a relacional, ou seja, ambas têm significado acional no texto. O quadro abaixo aponta sistematicamente essa relação de acordo com a mudança teórica.

\begin{tabular}{|c|c|c|c|c|}
\hline \multicolumn{2}{|c|}{$\begin{array}{l}\text { Halliday \& Matthiessen } \\
\text { (2004) }\end{array}$} & $\begin{array}{l}\text { Fairclough } \\
\text { (2001) }\end{array}$ & $\begin{array}{l}\text { Fairclough } \\
(2003)\end{array}$ & \\
\hline \multirow[b]{2}{*}{$\begin{array}{l}\text { Função } \\
\text { ideacional }\end{array}$} & Léxico & \multirow{2}{*}{$\begin{array}{l}\text { Função } \\
\text { ideacional }\end{array}$} & \multirow{2}{*}{$\begin{array}{l}\text { Significado } \\
\text { representa- } \\
\text {-cional }\end{array}$} & \multirow[t]{2}{*}{ Discurso } \\
\hline & Transitividade & & & \\
\hline \multirow{2}{*}{$\begin{array}{l}\text { Função } \\
\text { inter- } \\
\text { pessoal }\end{array}$} & \multirow[t]{2}{*}{ Modalizador } & $\begin{array}{l}\text { Função } \\
\text { relacional }\end{array}$ & $\begin{array}{l}\text { Significado } \\
\text { identifica- } \\
\text {-cional }\end{array}$ & Estilo \\
\hline & & $\begin{array}{l}\text { Função } \\
\text { identitária }\end{array}$ & \multirow{2}{*}{$\begin{array}{l}\text { Significado } \\
\text { acional }\end{array}$} & \multirow[t]{2}{*}{ Gênero } \\
\hline $\begin{array}{l}\text { Função } \\
\text { textual }\end{array}$ & Tema/rema & $\begin{array}{l}\text { Função } \\
\text { textual }\end{array}$ & & \\
\hline
\end{tabular}


A diferença maior - e que ocasiona toda essa proposta de modificação que Fairclough propõe ao trabalho da LSF - reside no fato de o primeiro não usar apenas o enunciado como objeto de estudo e análise, mas a estrutura global do texto. Isso resulta num olhar multifuncional sobre $o$ texto, que figura, para a ADTO, em três modos: modo de representar (discurso), modo de ser (estilo) e modo de agir (gênero). A seguir, abordaremos a análise de uma notícia para apontar a manifestação multifuncional do texto e avaliar criticamente o discurso, identificando esses três modos abordados por Fairclough.

\section{Um exemplo de análise}

O texto abaixo é uma notícia sobre a mobilização de homossexuais na cidade de São Paulo, publicado no jornal Folha de Pernambuco no dia 14 de junho de 2009. Trata-se de um exemplo no qual buscamos fazer uma análise sobre as formas do discurso funcionar como um modo de representar a ação noticiada (função ideacional ou significado representacional), de ser/identificar com essa ação (funções interpessoal e relacional ou significado identificacional) e de agir ou atuar como uma prática social específica (funções textual e relacional ou significado acional).

\section{(01)}

\section{PARADA GAY DEVE REUNIR 3,5 MILHÕES DE PESSOAS}

SÃO PAULO (Folhapress) - A $13^{\mathrm{a}}$ Parada Gay será realizada neste domingo em São Paulo e espera alcançar 3,5 milhões de participantes. No ano passado, o evento atraiu 3,4 milhões de pessoas, segundo a Associação da Parada do orgulho LGBT de São Paulo, número menor do que os 3,5 registrados em 2007.

O evento está programado para começar às $12 \mathrm{~h}$ em frente ao MASP, na avenida Paulista, onde acontece a concentração.

Os organizadores estimam que a dispersão do grupo deve acontecer por volta das $20 \mathrm{~h}$ na praça Roosevelt. Durante todo o percurso, o grupo será acompanhado por 20 trios elétricos, em sua maioria, ligados a ONGs e entidades sindicais como a UGT (União Geral dos trabalhadores) e a CUT (Central Única dos Trabalhadores).

Neste ano, o evento terá como tema "Sem Homofobia, Mais Cidadania Pela Isonomia dos Direitos!”. Atualmente, está em trâmite no Congres- 
so um projeto de lei que transformaria a homofobia em crime e prevê penas para pessoas com comportamentos e atitudes homofóbicas.

No mês passado, o ministro do Meio Ambiente, Carlos Minc, participou da marcha para comemorar o Dia Mundial de Combate à Homofobia e pela Paz e afirmou defender a tipificação da homofobia como crime.

As notícias podem servir, na sociedade atual, como uma ação social da reflexividade apresentada por Giddens (1990), uma vez que faz emergir informações consideradas importantes sobre o funcionamento social. Contudo, é ingênuo pensar que as notícias - como qualquer outro texto - estão isentas de ideologias. Além de informar, os textos jornalísticos também funcionam para desenvolver representações e estabelecer identidades e relações entre os interlocutores. $\mathrm{O}$ exemplo do texto acima é oportuno para apontarmos como a ideologia subjacente se manifesta e quais manobras ele produz para causar determinada reflexividade - compreensão - específica.

No início do texto, é possível observar o título, fator de contextualização cujo papel é fornecer expectativas sobre o que se lerá adiante. Nele, já é possível se fazer uma descrição da multifuncionalidade linguística. No que diz respeito ao fluxo informacional e sua função textual, a ordem das palavras não é aleatória, isso quer dizer que não é produzida por acaso, tem uma motivação por parte do produtor. A introdução "Parada Gay" cumpre, nesse caso, o papel de tema do enunciado, o que indica para o leitor o elemento principal da informação, que vem seguido de uma predicação, um rema ("deve reunir 3,5 milhões de pessoas"), aquilo que se fala sobre a informação principal. Nessa perspectiva, Halliday \& Matthiessen (2004) afirmam que o tema corresponde não só a um elemento importante, por isso ressaltado no início do enunciado, mas também a um elemento dado, ou conhecido, pelo interlocutor, ao contrário do rema, que consiste numa informação sobre o tema principal e que, por predicar acerca de um elemento conhecido é, do ponto de vista informacional, geralmente, um dado novo. Supondo que o título fosse "3,5 milhões de pessoas se reúnem hoje na Parada Gay", essa locação dos termos causaria outro efeito, uma vez que, conforme Halliday \& Matthiessen (2004), a atenção dada ao leitor para a informação "3,5 milhões de pessoas" não atribuiria a esse trecho a função de informação secundária, ou remática.

Para ilustrar um exemplo bastante marcado sobre a importância da 
ordem em enunciados, podemos citar um uso do sujeito tópico que fazemos como registro informal na oralidade. É comum acentuarmos o assunto sobre o qual queremos falar, usando-o no início do enunciado mesmo quando ele é retomado no fim. Por exemplo, ao dizer que gosta de um livro, o locutor pode usar um recurso de mudança na ordem sujeito, verbo, objeto (SVO), comumente na nossa língua portuguesa, para reforçar que seu assunto é o livro. Isto é, a oração "Eu gosto desse livro" - ordenado em SVO -, que é tematizado por "eu", termo dêitico que aponta para o locutor, pode ser falada como "Esse livro, eu gosto dele". Tal escolha de ordem não fortuita promove um foco diferenciado se comparado à outra ordem. Embora haja uma retomada do referente "livro" através da pronominalização "de + ele", o falante pode achar necessário apresentá-lo no início do enunciado, ou seja, na posição temática, o que revela para Fairclough (2003) uma ação do falante, por isso esse pesquisador categoriza tal função da linguagem como um significado acional.

Essa ordenação não ocorreu no título que apresentamos acima, ele é construído na forma canônica SVO. Contudo, a questão de identificar o tema é aplicada a qualquer ordem, portanto, no caso do título da notícia, é possível descrever o elemento temático como "Parada Gay", por sua posição no enunciado, e interpretar essa posição, à luz da teoria funcionalista da LSF, como uma escolha de foco sobre a informação que será veicula. Isso implica dizer, ainda, que podemos entender, por meio da forma, o possível propósito comunicativo do locutor partilhar a função da "Parada Gay" no texto: como assunto principal.

Uma vez demonstrando isso já no título, ou seja, na forma contextualizadora de apontar a expectativa do leitor, a notícia anuncia seu assunto. Cabe-nos perceber se esse tema é sustentado no texto .

Em relação à função ideacional proposta por Halliday \& Matthiessen (2004) e denominada por Fairclough $(2001,2003)$ de significado representacional, podemos, também no título, descrever como funciona. Essa função, para os autores citados, corresponde ao significado que a forma linguística exerce para representar os atores e as ações sociais no discurso e pode, para eles, ser identificada por meio da seleção lexical e da transitividade dos enunciados. No título que nós apresentamos, o assunto é lexicalizado como "Parada Gay". Atualmente, mesmo não sendo do conhecimento de todos, a proposta política dos movimentos internacionais de militância contra a homofobia e a favor dos direitos civis dos homossexuais reconhece o gay apenas como um dos representantes da orientação homo(sexual), uma 
vez que as lésbicas, os bissexuais e os transgêneros (travestis e transexuais) já passaram a empreender a causa outrora apenas pleiteada pelos homossexuais masculinos e serem inseridos no grupo LGBT. De forma que o jornalista, ao criar o título da notícia, não levou isso em consideração, mesmo tendo correferido a manifestação, no corpo do texto, como "Parada do Orgulho LGBT". A exclusão de representantes do grupo de homossexuais já inseridos nesse processo político fornece direcionamento de sentidos que o leitor fará na compreensão da notícia e do que seja a Parada.

Outro fator importante na análise da representação desse título é a transitividade desempenhada pelo enunciado. Entende-se por transitividade o processo sintático-semântico realizado pelos constituintes de um enunciado: participantes (sujeito e predicado); processo (verbo) e circunstância (adjunto adverbial). Além disso, essa categoria compreende a semântica do processo e o papel temático dos participantes, entre outras características. No título da notícia que selecionamos, "Parada Gay" assume o lugar de participante 1 e "3,5 milhões de pessoas", de participante 2. O primeiro realiza uma ação sobre o segundo e essa ação é formalizada pelo processo "reunir".

Halliday \& Matthiessen (2004) apresentam alguns tipos de processos, de acordo com uma quantidade de categorias semânticas que postula: material (ação concreta), verbal (ato de enunciação), mental (sentimentos e atividades cognitivas), entre outros. Logo, se categorizarmos o processo usado no título entre os tipos propostos por esses linguistas, poderíamos caracterizá-lo de "material", uma vez que a ação de reunir denota um acontecimento concreto.

O participante que reúne e aquele que é reunido, ou seja, o que pratica e o que recebe a ação também são categorizados, nesse caso, segundo a teoria hallidayana, como ator e objeto. Para efeito de representação, ao ator é criada uma imagem de agentividade e autonomia sobre o objeto, portanto, a partir desse título, o leitor pode inferir o potencial da Parada, isto é, dos homossexuais organizados naquele evento de militância política. A partir da semântica do processo, Halliday \& Matthiessen (2004) denominam de papel temático os sentidos atribuídos ao ator e ao objeto. É essa relação de dependência sintático-semântica entre os termos que esses autores denominam de transitividade. Já Fairclough (2003) se utiliza tanto da seleção lexical quanto da transitividade para afirmar que ambas expressam a imagem social que a notícia engendra no seu processo discursivo (produção e leitura). 
Quanto à função interpessoal (relacional e identitária ou identificacional) desse título, podemos destacar o uso do modalizador verbal "deve", que Fairclough (2003) classifica como modalizador epistêmico, pois funciona para emitir conhecimento relativo sobre o assunto, mas, sobretudo, indicar o grau de comprometimento do locutor. Ao dizer que a Parada "deve reunir", o locutor não assume a certeza da ação, mas lança possibilidade sobre ela, consequentemente atenuando a força agentiva do ator "Parada Gay". Seria diferente se o enunciado fosse, como conceitua a LSF, polarizado, ou seja, se fornecesse uma ação sem ressalvas: "Parada gay reúne 3,5 milhões de pessoas". Essa forma identificaria diferentemente a relação do locutor com o que diz, pois haveria a garantia do acontecimento (reunião de 3,5 milhões de pessoas).

Após esse preâmbulo acerca do título, desenvolveremos uma análise da notícia completa, separando, por questões didáticas, as considerações sobre cada função/significado.

\subsection{A função textual}

Dos cinco parágrafos que a notícia possui, quatro deles são tematizados por termos que remetem à Parada. Isso demonstra que o jornalista seguiu o foco do título no corpo do texto. Apenas o último parágrafo, como geralmente acontece nas notícias, não é dedicado às informações relacionadas ao assunto principal, assumindo natureza secundária naquilo que se quer informar. Os termos usados como tema são : "a $13^{\mathrm{a}}$ Parada Gay" e "o evento" (primeiro parágrafo); "o evento" (segundo parágrafo); "os organizadores" e "o grupo" (terceiro parágrafo); "o evento" e "o projeto de lei" (quarto parágrafo); "o ministro do Meio Ambiente" (quinto parágrafo). Todos os temas são relacionados à Parada e/ou aos homossexuais, com graus de aproximação semântica na seguinte ordem:

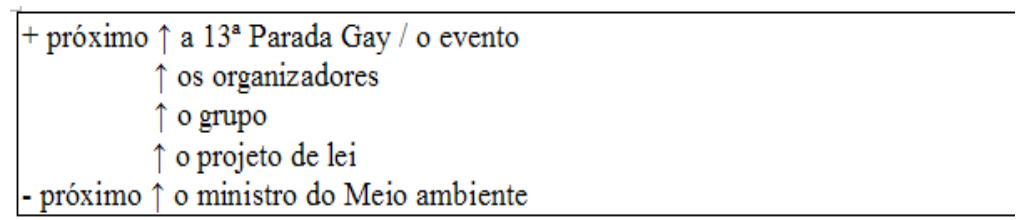

Gráfico 1 - Graus de aproximação semântica 
Se considerarmos que a Parada é o assunto e que LGBT formam o assunto subjacente, uma vez que são os atores e beneficiados da Parada, apresentamos a gradação com:

1. a "Parada" como primeiro elemento, o qual é retomado na notícia como "evento";

2. o termo "organizadores" como segundo elemento, pois já representa os próprios homossexuais ligados à Parada, elemento anterior;

3. "grupo" como terceiro elemento, porque aponta para os organizadores, mas também para aqueles que acompanham a Parada;

4. "projeto de lei", quarto elemento, uma vez que está ligado à Parada, embora o nome, per si, não identifique esse evento nem LGBT;

5. por último, "o ministro do Meio Ambiente", que, mesmo apoiando a Parada, não tem relação com o movimento.

Se observarmos a ordem de aparição desses temas no decorrer do texto, veremos que a gradação apresentada corresponde à sequência também da notícia, o que indica o mecanismo de exposição escolhido pelo locutor seguindo o fluxo informacional e semântico que abordamos. Nesse sentido, a permanência de palavras ligadas à Parada e ao homossexual na posição temática funciona como ação de prover a leitura do que vai ocorrer - a Parada - e o que o locutor deseja predicar, o foco de atenção do texto. Isso também reforça a representação da Parada e do homossexual na notícia, uma vez que a ocorrência dos termos citados como temas fornece visibilidade tanto à primeira quanto ao segundo. Contudo, a qualidade dessa representação, quais papéis ambos - Parada e homossexuais - ocupam no texto, só poderá ser analisado na relação entre o tema e o rema, ou seja, já na avaliação dos enunciados transitivos, que significa a análise de uma das categorias gramaticais responsáveis pela função ideacional.

\subsection{A função ideacional}

Para a análise da função ideacional, selecionamos as duas categorias supracitadas: o léxico e a transitividade. Em relação ao léxico escolhido, observamos a semântica das palavras usadas para se referirem à Parada e aos homossexuais, como referido no tópico anterior. Já sobre a transitividade, é preciso que nos dediquemos a perceber os mesmos mecanismos que observamos no título: a semântica dos processos e o papel temático dos participantes, além - quando for o caso - a semântica da circunstância. 
A forma de transitividade com voz passiva do processo está presente em três enunciados da notícia, todos eles revelam - como vimos - a Parada/o homossexual na posição temática, mas no papel de objeto:

1. "a $13^{\mathrm{a}}$ Parada gay será realizada";

2. "o evento está programado";

3. "o grupo será acompanhado por 20 trios elétricos".

As duas primeiras ocorrências apagam o ator das ações (quem realiza e quem programa) e a terceira apresenta um ator que não representa semanticamente a Parada ou o homossexual. Os processos usados nesses enunciados são materiais, ou seja, denotam forte agentividade.

Além desses três enunciados, a Parada e/ou o homossexual - como constatamos - é retomado em mais quatro enunciados transitivos. Em todos eles, esse assunto ocupa papel de ator, porém com processos distintos semanticamente:

1. "A $13^{\text {a }}$ Parada gay [...] espera alcançar 3,5 milhões de participantes";

2. "No ano passado, o evento atraiu 3,4 milhões de pessoas";

3. "Os organizadores estimam que a dispersão do grupo deve acontecer por volta das $20 \mathrm{~h}$ ";

4. "Neste ano, o evento terá como tema "Sem Homofobia, Mais Cidadania Pela Isonomia dos Direitos!".

O primeiro enunciado que se mostra é formado pelo processo composto "espera alcançar", onde há um processo modalizador (espera), que atenua o principal (alcançar) - e sobre o qual comentaremos no próximo tópico, relativo à função interpessoal. $\mathrm{O}$ recurso de modalizar o processo "alcançar" mitiga a ação real do participante " $13^{a}$ Parada Gay" no enunciado, colocando-a na condição de possibilidade. Isso atenua, também, o poder do ator, pela intervenção do processo auxiliar - modalizador.

O segundo enunciado representa uma ação agentiva: "o evento atraiu 3,4 milhões de pessoas". Contudo, a circunstância de tempo no passado diminui o poder do ator, uma vez que se afirma uma ação totalmente concluída no passado, ou seja, sem marcas de que ainda é vigente, portanto sem força atual.

O terceiro enunciado, tanto quanto os outros, aborda o assunto na posição de destaque, porém o uso do processo mental "estimar" caracteriza o tema ("organizadores") como experienciador, fornecendo-lhe agentividade, mas também baixo poder, já que não consiste numa prática de intervenção concreta, como o processo material. 
Sobre o quarto e último enunciado, podemos dizer que se trata do mais agentivo de todos eles, pois "o evento terá" algo, ou seja, é representado como uma entidade de poder, possuidora e dominante. Porém, seu objeto, isto é, o que ele detém consiste numa proposta criada por ele mesmo (o evento ou os organizadores). $\mathrm{O}$ alcance de governo do ator social nesse enunciado é limitado, uma vez que não se trata de ter algo além daquilo que faz parte do seu próprio contexto.

Diante da descrição desses enunciados transitivos, reconhecemos que essa notícia aponta, como sugere Fairclough (2003), para a representação de baixa autonomia, inclusão e poder de governo dos homossexuais. Mesmo havendo visibilidade de LGBT, pois a posição temática que assumem destaca-os, os alcances de atuação são limitados, seja por meio da atribuição passiva, pela agentividade atenuada por modalizador e circunstância de tempo, ou seja, pelo papel temático de beneficiário.

\subsection{A função interpessoal}

Sobre a função interpessoal, daremos atenção precisa à modalidade, que se manifestou na notícia que apresentamos apenas na forma verbal e em dois momentos, no título e no parágrafo inicial por meio da forma composta "espera alcançar". Como afirmamos no tópico anterior, o processo "esperar" atua sobre a ação atenuando-a e, além disso, retirando a responsabilidade do locutor em assegurar um acontecimento real. A utilização desse processo modaliza o processo seguinte, dando a ele o caráter de hipótese.

Halliday \& Matthiessen (2004) afirmam que o papel do modalizador é pôr em um plano intermediário a pontualidade dos acontecimentos, isto é, não assegurar a realização de uma ação, ou não garantir a polaridade de uma ação. Para eles, a ocorrência de um evento (polo positivo) ou a negação do mesmo (polo negativo) indica pontos extremos de um acontecimento, sendo, portanto o intermédio entre esses pontos, ou polos, a possibilidade positiva ou negativa do acontecimento, como mostra o gráfico a seguir:

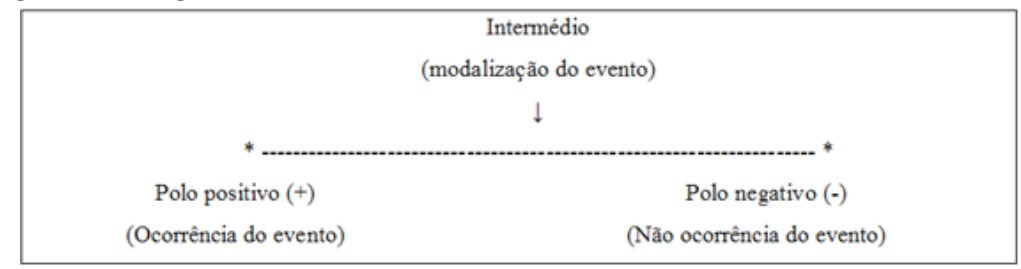

Gráfico 2 - Modalização 
Ao destacar a posição intermediária, o locutor indica que não se compromete com alguma das polaridades, ou seja, com a certeza da ocorrência ou negação dela. A manifestação desse ponto intermediário Halliday \& Matthiessen (2004) chamam de modalidade e afirmam ser materializado na forma de processos e circunstâncias (verbos e advérbios). Já Fairclough (2003) inclui os polos no processo de modalização e denomina qualquer um dos pontos (polos positivo e negativo, bem como o intermédio) como um fator de modalização, nomeado por ele de modalização categórica. Esse teórico amplia a proposta da LSF e defende que qualquer expressão do acontecimento (polarizada ou intermediária) compromete o locutor e estabelece uma relação entre este e o que diz.

Diante disso, seguindo a perspectiva de Fairclough, podemos afirmar que houve modalização em toda a notícia que analisamos, no entanto em alguns momentos (no título e no enunciado "A 13 $3^{\text {a }}$ Parada [...] espera alcançar 3,5 milhões de pessoas") o locutor se identifica com menos responsabilidade sobre o que diz. Assim, podemos perceber que, do ponto de vista relacional e identitário, é atribuída à postura do jornalista, ao enunciar essa notícia, o comprometimento com o que informa.

\section{Considerações finais}

Este artigo buscou oferecer a topicalização de um estudo sobre a multifuncionalidade da linguagem, tomando como orientação o legado teórico de Michael Halliday e Norman Fairclough. Na análise que exemplificamos, demos relevância ao estudo dos mecanismos que fornecem os significados textual, ideacional e interpessoal aos textos, isto é, respectivamente, a função de informar ou dar visibilidade, representar atores e ações e caracterizar o grau de envolvimento do locutor com o conteúdo ou com o interlocutor.

A notícia que analisamos serviu para exibirmos a importância da Análise Crítica do Discurso em qualquer texto, desde que nossos propósitos apontem para o desvelamento de estruturas capazes de representar e construir identidades e sistema de crenças e conhecimento dados como naturais nos textos. É diante disso que nossa análise ofereceu a oportunidade de visualizarmos o quanto a abordagem multifuncional é capaz de identificar a constituição (latente ou manifesta, limitada ou com grande alcance) de grupos minoritários, como os homossexuais, em textos jornalísticos. 


\section{WHEN THE DISCOURSES STUDIES JOIN THE LGBT STUDIES}

\section{ABSTRACT}

This work is theoretical-analytical and aims at identifying the panoramic studies of linguists Michael Halliday \& Christian Matthiessen (2004) and Norman Fairclough (2001, 2003), noting the points of encounter and difference between their two approaches. We present a comparative exposure through data that demonstrate the concepts and the most profitable linguistic categories about representation to these scientists. We apply the theoretical proposal developed by them in the analysis of a news story about the representation of LGBT activism (lesbian, gay, bisexual and transgender), to verify the relevance and critical social theory advocated by the authors cited.

KEY-WORDS: Language. Multifunctionality. LGBT.

\section{REFERÊNCIAS}

FAIRCLOUGH, Norman. Critical and descriptive goals in discourse analysis. Journal Pragmatics n. 9, p. 739-63, 1985 . Language and power. Londres: Longman, 1989 UnB, 2001.

. Discurso e mudança social. Tradução Maria Izabel Magalhães. Brasília:

Analysing Discourse. Textual analysis for social research. London \& New York: Routledge, 2003.

GIDDENS, Anthony. As consequências da modernidade. São Paulo: UNESP, 1990.

HALLIDAY, Michael; MATTHIESSEN, Christian. An introduction to functional grammar. London: Edward Arnold, 2004.

NEVES, Maria Helena de Moura. A gramática funcional. São Paulo: Martins Fontes, 1997. 
RESENDE, Viviane \& RAMALHO, Viviane. Análise de discurso crítica. São Paulo: Contexto, 2006.

\section{NOTAS}

${ }^{1}$ Este texto faz parte do corpus de nossa pesquisa sobre a representação de LGBT em jornais, desenvolvida entre os anos 2008 e 2013, sob orientação da professora Maria Lucia Victorio de Andrade, no curso de doutorado em Filologia e Língua Portuguesa na Universidade de São Paulo.

${ }^{2}$ Em muitas notícias, ocorre o desfoque do assunto no corpo do texto como manobra argumentativa e ideológica. É papel da ACD observar essa estratégia.

${ }^{3}$ Muitos estudiosos da LSF compreendem que a categorização semântica dos processos é um procedimento escorregadio, pois depende de fatores como registros, estilo etc. Por exemplo, o processo "reunir" dessa notícia pode ser entendido como uma metáfora de "possibilitar" ou "motivar a reunião",já que reunir implica um ato empírico de agrupar alguém ou algo, cabendo, desse modo, apenas aos organizadores da Parada.

${ }^{4}$ Nesse título, não há nenhuma circunstância ("hoje", "em São Paulo" etc.). Se houvesse, deveria ser analisada também a relação que ela estabelece com os outros constituintes (participantes e processo).

Recebido em: 22/10/2016

Aceito em: 09/06/2017 